\title{
Factors associated with caesarean deliveries among child-bearing women in Pakistan: secondary analysis of data from the Demographic and Health Survey, 2012-13
}

\author{
Aaisha Amjad ${ }^{1}$, Uzair Amjad ${ }^{1}$, Rubeena Zakar ${ }^{1}$, Ahmed Usman ${ }^{1}$, Muhammad Zakria Zakar ${ }^{1}$ and Florian Fischer ${ }^{2 *}$
}

\begin{abstract}
Background: The increasing rate of caesarean deliveries has become a serious concern for public health experts globally. Various medical and non-medical factors, such as maternal socio-demographics, are found to be responsible for this upsurge. Like in other countries, the rate of caesarean sections has increased in Pakistan as well. Therefore, there is a need to investigate the factors behind this increase. This study aims to assess the determinants associated with caesarean deliveries among child-bearing women aged 15-49 years in Pakistan.

Methods: Secondary data analysis was conducted on nationally representative cross-sectional survey data from the Pakistan Demographic and Health Survey, 2012-2013. The analysis was limited to mothers aged 15-49 years, who had given birth to at least one child during the 5 years immediately preceding the survey $(n=7461)$. Maternal sociodemographic characteristics and pregnancy-related variables, including antenatal care utilisation, place of delivery and pregnancy complications were considered as independent variables. The association between caesarean section deliveries (outcome variable) and its determinants was assessed by calculating unadjusted and adjusted odds ratios with 95\% confidence intervals using a multivariable binary logistic regression.

Results: Of the women who had given birth to at least one child during the previous 5 years, the percentage of mothers who delivered their babies through caesarean section was found to be 13.6\%. The likelihood of caesarean deliveries was associated with mothers aged more than 24 years, women residing in Punjab province, women belonging to the richest class, women with higher education, women employed at professional/managerial/technical level, and women residing in an urban setting. Additionally, the women who had pregnancy complications, a high utilisation of antenatal care and delivered their babies in private hospitals were found to have higher chances of caesarean deliveries.

Conclusions: The study revealed that there are a high percentage of women delivering babies through caesarean section in Pakistan. Therefore, strict measures need to be taken to deal with this concern. For example, detailed medical justifications by doctors for performing caesarean sections and awareness among women regarding the reduction of pregnancy complications can help to reduce the chances of malpractice related to caesarean deliveries.
\end{abstract}

Keywords: Caesarean delivery, Vaginal delivery, Pregnancy complication, Antenatal visit

\footnotetext{
* Correspondence: f.fischer@uni-bielefeld.de

${ }^{2}$ Department of Public Health Medicine, School of Public Health, Bielefeld

University, Bielefeld, Germany

Full list of author information is available at the end of the article
}

(c) The Author(s). 2018 Open Access This article is distributed under the terms of the Creative Commons Attribution 4.0 International License (http://creativecommons.org/licenses/by/4.0/), which permits unrestricted use, distribution, and reproduction in any medium, provided you give appropriate credit to the original author(s) and the source, provide a link to the Creative Commons license, and indicate if changes were made. The Creative Commons Public Domain Dedication waiver (http://creativecommons.org/publicdomain/zero/1.0/) applies to the data made available in this article, unless otherwise stated. 


\section{Background}

The role of caesarean section deliveries is acknowledged worldwide for dealing with complications related to childbirth and reducing the mortality rates of mother and foetus [1]. However, during the last decade, the increase in caesarean section deliveries has become a matter of serious concern for public health experts globally [2]. In most countries, the caesarean section rate (CSR) has exceeded the level of $10-15 \%$ recommended by the World Health Organization (WHO) [1]. Among highincome countries, CSR is $30.3 \%$ in the USA, $22 \%$ in the United Kingdom, 26\% in Canada, 19\% in France, 28\% in Germany and $30 \%$ in Australia [2]. Similarly, in lowincome countries, CSR is increasing on a yearly basis. For example, in Bangladesh, caesarean deliveries increased from 2\% (2000) to 17\% (2011); in India from 3\% (1992) to $11 \%$ (2006) and in Nepal from 1\% (2000) to 5\% (2011) [3]. Similarly, an increasing rate of caesarean deliveries has been documented in Pakistan. The findings of studies conducted in different areas of Pakistan report a current CSR of 16-20\%, approximately [4, 5].

Increasing CSR worldwide has prompted public-health professionals to discuss the medical and non-medical determinants responsible for this increase [6]. Certain obstetric risks such as dystocia, previous caesarean section, foetal distress, breach births, post-term pregnancy, multiple pregnancy and hypertensive disorder are considered to be justifiable medical reasons for caesarean deliveries [7, 8]. Furthermore, socio-demographic, cultural and psychological factors may also influence the increase in CSR [6]. Maternal socio-demographics such as age, social class, education, occupation and type of residence have been found to be strongly correlated with the type of delivery [9]. In terms of cultural aspects, studies have shown that the cultural context plays a pivotal role in constructing the patterns of women's behaviour towards pregnancyrelated issues and mode of delivery [10-12]. Additionally, psychological factors which may be due to fear related to prolonged labour and vaginal delivery pain reinforce women's preferences for caesarean delivery [13].

Furthermore, doctors' decisions and patient demand are contributing factors affecting the escalation of CSR across the globe [14]. In developed countries, where patients are given the option to choose between vaginal and caesarean delivery, women's preference for caesarean delivery has appeared as an important determinant [15]. In developing countries, doctors' referrals to perform caesarean surgery appear to be a more significant determinant than the woman's preference [16].

The high rate of caesarean deliveries in both developed and developing countries also underlines the growing medicalisation of the childbirth process [6]. Over the past few years, a greater reliance on medical technology to deal with childbirth complications has resulted in increasing rates of caesarean deliveries [17, 18]. This medicalisation of childbirth has also increased concerns regarding malpractice associated with the use of medical technology by doctors, who may perform unnecessary caesareans for their own convenience, quick handling to save time or economic incentives [19]. Moreover, expectant mothers' inadequate knowledge about childbirth complications is likely to increase the chances of their exploitation for economic gain. In such cases, doctors and hospital authorities might easily persuade patients to opt for caesarean deliveries by associating the method with the security of mother and child health, even when the baby could be delivered normally [20].

The discussion mentioned above underlines several medical and non-medical factors that lie behind high CSR in different countries across the world. However, despite an alarming increase in CSR, there is a paucity of literature systematically investigating the determinants associated with the increase in caesarean deliveries in Pakistan. Given this background, this paper aims to assess the maternal socio-demographic characteristics and pregnancy-related variables associated with caesarean deliveries among childbearing women aged 15-49 years in Pakistan.

\section{Methods \\ Sample of participants}

Secondary data analysis was used to analyse data obtained from the Pakistan Demographic and Health Survey (PDHS) 2012-13 [21]. This was the third time the global programme of Demographic and Health Surveys had conducted the survey in Pakistan. The main aim was to provide updated and reliable data on fertility and family planning, childhood mortality, maternal and child health, women's and children's nutritional status, women's empowerment, domestic violence and knowledge about HIV/AIDS. The PDHS dataset comprises a nationally representative household-based sample of 12,943 households, selected by using a two-stage, stratified, random sample design. However, owing to security and political reasons, the Federally Administered Tribal Areas, the Federally Administered National Areas, Azad Jammu and Kashmir, and restricted military areas were excluded from the survey.

During the first stage, the whole area, comprising of urban and rural regions of four provinces in Pakistan and Gilgit Baltistan, was divided into mutually exclusive smaller areas known as enumeration blocks. About 200-250 households were situated in each enumeration block, and these were further classified into low, middle and high income categories. In the second stage, households situated in both urban and rural areas were selected by using a systematic random sampling technique. Out of 12,943 households interviewed, a total of 14,569 ever-married women aged 15-49 years were 
identified, of whom 13,558 were successfully interviewed by using individual women's questionnaires, a response rate of 93\%. Depending upon the preferences of household members, trained interviewers conducted a verbally administered survey in their national or regional language. Detailed methodology, with complete information on survey design and data collection, has been published elsewhere [21]. For this study, the data was limited to mothers aged 15-49 years who had given birth during the previous 5 years $(n=7461)$.

\section{Survey instrument and data management}

Maternal socio-demographic characteristics and pregnancyrelated variables, including antenatal care utilisation, place of delivery and pregnancy complications, were considered as independent variables. Maternal sociodemographic variables were assessed through questions related to the mother's age when she gave birth $(<18$, 18-20, 21-24, > 24 years), level of education (no education, primary, middle, secondary, or higher education), area of residence (urban, rural), national region of residence (Punjab, Sindh, Balochistan, Khyber Pukhtunkhwa, Gilgit Baltistan, or Islamabad Capital Territory). Depending upon the possession of consumer items and residential characteristics, the wealth index was measured in quintiles (poorest, poorer, middle, richer, richest). Mothers' employment status was assessed through a question asking whether they were working at the time of interview. The working mothers were subdivided into categories (unskilled, skilled, or professional/managerial/technical), whereas non-employed mothers were placed in the category of "not working". The birth order of children born to the women during the previous 5 years was recoded as " 1 ", " $2-3$ ", " $4-5$ ", " 6 or more". The birth order refers to the order of a child born in his/her family. Considering the recommendations of the WHO [22], a woman without pregnancy complications should have at least four antenatal visits to reduce the probability of adverse pregnancy outcomes. Keeping this aspect in mind, the number of antenatal visits of the mothers during pregnancy was categorised as "None", "13 " or " 4 and more". Pregnancy complications were assessed with the help of a question investigating whether the mothers were informed about any pregnancy complications during their antenatal visits or not. The response category for pregnancy complications was termed "Yes" for those women who had a medical history of health problems such as anaemia, hypertension, diabetes and/or haemorrhage during pregnancy. Similarly, the mothers were asked where they had delivered their babies. The place of delivery was recoded as "private" or "public" sectors, excluding those cases of deliveries which took place at home, because caesarean section deliveries cannot be performed at home. In the Pakistani context, the public sector includes government hospitals and rural health centres while the private sector includes private hospitals and clinics.

Caesarean section was used as the outcome variable. It was assessed by asking mothers whether their last-born baby during the previous 5 years was delivered by caesarean section or not. In the PDHS, the birth of children by caesarean section was defined as "delivery by caesarean section", and the response categories were termed "Yes" and "No". However, data were not available to differentiate between medically indicated and nonmedically indicated cases of caesarean deliveries.

\section{Statistical analysis}

All the data were weighted and SPSS version 21 was used to analyse the secondary data obtained from the PDHS to account for women who delivered by caesarean section versus women who did not. Weighting was performed to account for the complex sampling design and allows us to generalise our findings to all women in Pakistan. Descriptive statistics for both groups and maternal sociodemographic variables were presented as frequency distributions and percentages. We calculated weighted percentages of the national population from the original sample. We assessed the association between caesarean section deliveries and its determinants by calculating unadjusted odds ratios (OR) and adjusted odds ratios (AOR) with $95 \%$ confidence intervals (CI). A simple binary logistic regression analysis was carried out to assess the relationship between deliveries by caesarean section and the independent variables. In the multivariate logistic regression analysis, the inclusion of independent variables was based on a significance level of $p<0.05$. The AOR was obtained by simultaneously entering all the independent variables that were found to be significant at less than 0.05 level in the bivariate analyses.

\section{Results}

\section{Maternal socio-demographic characteristics}

Of the women who had given birth during the previous 5 years $(n=7461), 32.1 \%$ were in the age range of 21 24 years. In terms of education, $55.8 \%$ never attended school. $72.2 \%$ were non-working mothers and $22.8 \%$ belonged to the poorest quintile of wealth. As far as the region and place of residence was concerned, it was found that more than half of the mothers (69.9\%) resided in rural areas, while $56.1 \%$ were inhabitants of Punjab province (Table 1).

Of the women who had given birth to at least one child during the previous 5 years, the percentage of mothers who delivered their babies through caesarean section was found to be $13.6 \%(n=1014)$. 
Table 1 Socio-demographic characteristics of child-bearing women aged $15-49$ years

\begin{tabular}{|c|c|c|}
\hline \multirow[t]{2}{*}{ Variables } & $\begin{array}{l}\text { Number of } \\
\text { participants }\end{array}$ & $\begin{array}{l}\text { Weighted } \\
\text { percentage }\end{array}$ \\
\hline & \multicolumn{2}{|l|}{$n=7461$} \\
\hline \multicolumn{3}{|l|}{ Mother's age at birth (in years) } \\
\hline Less than 18 & 2025 & 27.2 \\
\hline $18-20$ & 1661 & 22.3 \\
\hline $21-24$ & 2394 & 32.1 \\
\hline More than 24 & 1367 & 18.4 \\
\hline \multicolumn{3}{|l|}{ Mother's education } \\
\hline No education & 4155 & 55.8 \\
\hline Primary & 1230 & 16.5 \\
\hline Middle & 587 & 7.9 \\
\hline Secondary & 792 & 10.6 \\
\hline Higher & 682 & 9.2 \\
\hline \multicolumn{3}{|l|}{ Mother's occupation } \\
\hline Not working & 5378 & 72.2 \\
\hline Unskilled & 938 & 12.6 \\
\hline Skilled & 990 & 13.3 \\
\hline Professional/Technical/Managerial & 140 & 1.9 \\
\hline \multicolumn{3}{|l|}{ Wealth index } \\
\hline Poorest & 1698 & 22.8 \\
\hline Poorer & 1544 & 20.7 \\
\hline Middle & 1464 & 19.7 \\
\hline Richer & 1469 & 19.4 \\
\hline Richest & 1272 & 17.1 \\
\hline \multicolumn{3}{|l|}{ Type of residence } \\
\hline Urban & 2244 & 30.1 \\
\hline Rural & 5202 & 69.9 \\
\hline \multicolumn{3}{|l|}{ Region } \\
\hline Punjab & 4180 & 56.1 \\
\hline Sindh & 1714 & 23.0 \\
\hline Khyber Pakhtunkhwa & 1117 & 15.0 \\
\hline Balochistan & 348 & 4.7 \\
\hline Gilgit Baltistan & 56 & 0.7 \\
\hline Islamabad Capital Territory & 31 & 0.4 \\
\hline
\end{tabular}

\section{Determinants of caesarean deliveries \\ Simple binary logistic regression}

The data shows that women aged more than 24 years $(\mathrm{OR}=5.001 ; 95 \% \mathrm{CI}: 4.041-6.187)$ and with a child at first birth order $(\mathrm{OR}=5.059$; 95\% CI: 3.953-6.475) have a higher chance of delivering babies by caesarean section. As far as the maternal socio-economic status was concerned, the probability of caesarean deliveries was higher among mothers belonging to the richest class $(\mathrm{OR}=11.421 ; 95 \% \mathrm{CI}$ : 8.681-15.027), having higher education $(\mathrm{OR}=7.860 ; \quad 95 \% \quad \mathrm{CI}: \quad 6.509-9.492) \quad$ and employed at professional/technical/managerial levels $(\mathrm{OR}=2.147 ; 95 \% \mathrm{CI}: 1.527-3.020)$. Similarly, the odds of caesarean deliveries were higher among the mothers residing in urban areas (OR $=2.425$; 95\% CI: 2.115-2.780). Additionally, women who had high a high risk of pregnancy complication (OR $=1.677$; 95\% CI: $1.453-1$. 936) and received antenatal care more than four times $(\mathrm{OR}=25.4$; 95\% CI: 17.219-37.471) had greater chances of delivering babies through caesarean section. Moreover, the women who delivered babies in private hospitals (OR: 1.326; 95\% CI: 1.140-1.53) were found to have higher probability of undergoing caesarean delivery (Table 2).

\section{Multivariable logistic regression}

Using multivariable logistic regression analysis, the data showed that women with pregnancy complications (AOR $=1.307$; $95 \%$ CI: 1.107-1.545), and who utilised antenatal care more than four times $(\mathrm{AOR}=2.811 ; 95 \% \mathrm{CI}: 1.823-4$. 33) had higher chances of delivering babies by caesarean. Similarly, women age at first birth more than 24 years $(\mathrm{AOR}=1.883$; 95\% CI: $1.452-2.438)$ were found to have a greater chance of giving birth by caesarean section than younger women. Women who lived in Punjab province $(\mathrm{AOR}=1.911 ; 95 \% \mathrm{CI}: 1.457-2.506)$ were more likely to deliver children by caesarean section. Contrarily, women living in Baluchistan (AOR = 0.376; 95\% CI: 0.228-0.622) had lower risk of caesarean deliveries as compared to Islamabad. Women belonged to the richest class (AOR = 1.588; CI: 1.036-2.435) were found to have a higher probability of delivering through caesarean section. Additionally, the women who delivered babies in private hospitals $(\mathrm{AOR}=1.052 \mathrm{CI}: 0.883-1.254)$ had a greater chance of caesarean deliveries (Table 3 ).

\section{Discussion}

The prevalence of caesarean deliveries among women in Pakistan rose from $7.3 \%$ in 2008 to $14 \%$ in 2013 [21, 23]. Various studies conducted at local hospitals in Pakistan have highlighted obstetric risks such as foetal distress, failed induction, wound sepsis, repeated caesarean and massive haemorrhage as the medical causes of increasing CSR [24-26]. The cultural belief that caesarean is a symbol of better socio-economic status [11] could also be a possible reason for the increasing rate of caesarean deliveries. However, in developing countries like Pakistan, caesareans are not performed on the demand of the patient; rather, the doctor generally determines the choice of a caesarean delivery [6]. Therefore, another factor influencing the caesarean rate in the Pakistani context could be the referrals of doctors [27].

Among the socio-demographic characteristics of mothers, the association between maternal age and 
Table 2 Simple binary logistic regression for the predictors associated with cesarean section among women aged 15-49 years

\begin{tabular}{|c|c|c|c|c|c|}
\hline \multirow[t]{2}{*}{ Socio-demographic characteristics } & \multicolumn{2}{|c|}{ Delivery by caesarean (weighted percentage) } & \multirow[t]{2}{*}{ OR } & \multirow[t]{2}{*}{$95 \% \mathrm{Cl}$} & \multirow[t]{2}{*}{$p$-value } \\
\hline & No & Yes & & & \\
\hline \multicolumn{6}{|l|}{ Mother's age at birth (in years) } \\
\hline Less than 18 & 92.8 & 7.2 & 1 & & \\
\hline $18-20$ & 88.1 & 11.9 & 1.658 & $1.307-2.103$ & $<0.001$ \\
\hline $21-24$ & 81.1 & 18.9 & 2.743 & $2.231-3.372$ & $<0.001$ \\
\hline More than 24 & 72.4 & 27.6 & 5.001 & $4.041-6.187$ & $<0.001$ \\
\hline \multicolumn{6}{|l|}{ Children birth order } \\
\hline More than 6 & 93.9 & 6.1 & 1 & & \\
\hline 1 & 74.5 & 25.5 & 5.059 & $3.953-6.475$ & $<0.001$ \\
\hline $2-3$ & 80.4 & 19.6 & 3.425 & $2.706-4.334$ & $<0.001$ \\
\hline $4-5$ & 89.5 & 10.5 & 1.558 & $1.189-2.042$ & $<0.001$ \\
\hline \multicolumn{6}{|l|}{ Mother's education } \\
\hline No education & 92.5 & 7.5 & 1 & & \\
\hline Primary & 82.9 & 17.1 & 2.661 & $2.150-3.294$ & $<0.001$ \\
\hline Middle & 78.7 & 21.3 & 3.519 & $2.737-4.523$ & $<0.001$ \\
\hline Secondary & 68.5 & 31.5 & 5.221 & $4.262-6.397$ & $<0.001$ \\
\hline Higher & 59.8 & 40.2 & 7.860 & $6.509-9.492$ & $<0.001$ \\
\hline \multicolumn{6}{|l|}{ Mother's occupation } \\
\hline Not working & 81.9 & 18.1 & 1 & & \\
\hline Unskilled & 88.6 & 11.4 & 0.759 & $0.599-0.962$ & 0.023 \\
\hline Skilled & 94.7 & 5.3 & 0.355 & $0.248-0.507$ & $<0.001$ \\
\hline Professional/Technical/Managerial & 70.0 & 30.0 & 2.147 & $1.527-3.020$ & $<0.001$ \\
\hline \multicolumn{6}{|l|}{ Wealth index } \\
\hline Poorest & 94.5 & 5.5 & 1 & & \\
\hline Poorer & 93.0 & 7.0 & 1.622 & $1.167-2.255$ & $<0.001$ \\
\hline Middle & 88.1 & 11.9 & 2.456 & $1.801-3.348$ & $<0.001$ \\
\hline Richer & 76.4 & 23.6 & 5.487 & $4.123-7.303$ & $<0.001$ \\
\hline Richest & 64.7 & 35.3 & 11.421 & $8.681-15.03$ & $<0.001$ \\
\hline \multicolumn{6}{|l|}{ Type of residence } \\
\hline Rural & 88.5 & 11.5 & 1 & & \\
\hline Urban & 74.4 & 25.6 & 2.425 & $2.115-2.780$ & $<0.001$ \\
\hline \multicolumn{6}{|l|}{ Region } \\
\hline Islamabad Capital Territory & 71.9 & 28.1 & 1 & & \\
\hline Punjab & 80.9 & 19.1 & 0.709 & $0.563-0.894$ & $<0.001$ \\
\hline Sindh & 82.6 & 17.4 & 0.655 & $0.516-0.832$ & $<0.001$ \\
\hline Khyber Pakhtunkhwa & 94.8 & 5.2 & 0.203 & $0.153-0.269$ & $<0.001$ \\
\hline Baluchistan & 98.3 & 1.7 & 0.061 & $0.039-0.095$ & $<0.001$ \\
\hline Gilgit Baltistan & 96.4 & 3.6 & 0.156 & $0.106-0.229$ & $<0.001$ \\
\hline \multicolumn{6}{|l|}{ Pregnancy complication } \\
\hline No & 85.1 & 14.9 & 1 & & \\
\hline Yes & 74.8 & 25.2 & 1.677 & $1.453-1.936$ & $<0.001$ \\
\hline \multicolumn{6}{|l|}{ Antenatal care utilization } \\
\hline None & 97.9 & 22.1 & 1 & & \\
\hline $1-3$ & 89.3 & 10.7 & 6.212 & 4.147-9.307 & $<0.001$ \\
\hline
\end{tabular}


Table 2 Simple binary logistic regression for the predictors associated with cesarean section among women aged 15-49 years (Continued)

\begin{tabular}{|c|c|c|c|c|c|}
\hline \multirow[t]{2}{*}{ Socio-demographic characteristics } & \multicolumn{2}{|c|}{ Delivery by caesarean (weighted percentage) } & \multirow[t]{2}{*}{ OR } & \multirow[t]{2}{*}{$95 \% \mathrm{Cl}$} & \multirow[t]{2}{*}{$p$-value } \\
\hline & No & Yes & & & \\
\hline More than 4 & 69.9 & 30.1 & 25.401 & $17.219-37.471$ & $<0.001$ \\
\hline \multicolumn{6}{|l|}{ Place of delivery } \\
\hline Public & 71.1 & 28.9 & 1 & & \\
\hline Private & 68.8 & 31.2 & 1.326 & $1.140-1.543$ & $<0.001$ \\
\hline
\end{tabular}

Abbreviations: 1 reference category, OR odds ratio, $\mathrm{Cl}$ confidence interval

${ }^{1}$ By using $X^{2}$ test

mode of delivery is found to be an important factor [28]. Several pieces of research have demonstrated that the chance of caesarean delivery is higher among older mothers [29]. Similarly, our data found that the probability of delivery by caesarean increases with rising age of the mother. While the reasons for the increased number of caesarean deliveries among older women are still uncertain, it is believed that older mothers are more prone to pregnancy complications that may lead to caesarean deliveries [30]. In Pakistan, the rising trend among women of getting married or conceiving at a later age due to their orientation towards career, educational, financial and other goals tends to increase their chances of undergoing caesarean delivery [31]. Thus, this may possibly be a factor in the upsurge in the rate of caesarean sections in Pakistan.

The literature has shown that women who report chronic health problems (including chronic hypertension, cardiac disease, lung disease or other medical risk factors) are more likely to undergo caesarean section [3]. Supporting the results of these studies, our data also shows that women who were reported to have pregnancy complications such as anaemia, hypertension, haemorrhage, or diabetes during pregnancy had a greater likelihood of caesarean delivery.

Clinical studies have shown that antenatal care utilisation, pregnancy complications and mode of delivery are interlinked [32]. Keeping in view the significance of antenatal care utilisation in determining the mode of delivery, the WHO recommends every pregnant woman to have at least four antenatal care visits during her pregnancy [22]. Similarly, the literature elucidates that antenatal care serves as a precautionary measure to prevent complications which may lead to caesarean sections [7]. In contrast, our data shows that mothers who received antenatal care more than four times delivered babies by caesarean section. Although the reason for this is still unclear, the risk-avoiding behaviour of gynaecologists towards women who reported having pregnancy complications could be one of the reasons for this preference for caesarean delivery.

In terms of regional demographics, the findings of this study indicate that mothers living in Punjab province have a higher probability of undergoing caesarean section; the reason could be the easy access, availability and utilisation of maternal healthcare facilities at private and public hospitals in the province [4]. On the other hand, limited access to health facilities, poor maternal socioeconomic status and lower educational level can be identified as important factors associated with a lesser likelihood of caesarean section in other provinces.

Studies conducted in different South Asian countries, including Bangladesh, India and Nepal, suggest that women with a higher socio-economic background are more likely to undergo caesarean section [3]. Likewise, literature from other countries indicates that the rate of caesareans was higher among mothers with higher socioeconomic status [33]. Correspondingly, the findings of our study also show that mothers with better socio-economic status are more likely to opt for caesarean deliveries than their poorer counterparts. Arguably, mothers belonging to a higher socio-economic class have adequate financial resources to afford the expense of a caesarean section.

Although the role of caesarean delivery in reducing maternal and neonatal deaths has been widely acknowledged, the possibility of malpractice associated with this surgical procedure is also on the increase [6]. When discussing its misuse, several studies argue that in developing countries the rate of caesarean deliveries is higher in private hospitals than public hospitals because of the financial benefits $[3,33]$. Conversely, our study has found that the rate of caesarean deliveries is increasing in both private and public-sector hospitals in Pakistan without significant variation. Arguably, the malpractice associated with caesarean deliveries may exist in both settings for different reasons. For instance, the high operating expenses of performing a caesarean procedure may be identified as one of the reasons that has led to an increase in the caesarean delivery rate in private hospitals. Whereas, in the case of public hospitals, the desire of doctors to improve their surgical experience, a shortage of paramedical staff, a need for quick handling and convenience may be considered as other possible reasons for the increase in caesarean deliveries [34]. However, the PDHS (2012-2013) does not provide any data to distinguish between medically indicated 
Table 3 Adjusted odd ratios for multivariable logistic regression of factors independently associated with among women aged 15-49 years

\begin{tabular}{|c|c|c|c|}
\hline Variables & AOR & $95 \% \mathrm{Cl}$ & p-value \\
\hline \multicolumn{4}{|l|}{ Mother's age at birth (years) } \\
\hline Less than 18 & 1 & & \\
\hline $18-20$ & 1.134 & $0.866-1.485$ & 0.360 \\
\hline $21-24$ & 1.479 & $1.161-1.884$ & 0.002 \\
\hline More than 24 & 1.883 & $1.452-2.438$ & $<0.001$ \\
\hline \multicolumn{4}{|l|}{ Children birth order } \\
\hline More than 6 & 1 & & \\
\hline 1 & 1.208 & $0.909-1.606$ & 0.193 \\
\hline $2-3$ & 1.282 & $0.959-1.713$ & 0.093 \\
\hline $4-5$ & 0.901 & $0.656-1.239$ & 0.523 \\
\hline \multicolumn{4}{|l|}{ Mother's education } \\
\hline No education & 1 & & \\
\hline Primary & 1.047 & $0.808-1.358$ & 0.727 \\
\hline Middle & 1.018 & $0.749-1.385$ & 0.908 \\
\hline Secondary & 1.164 & $0.889-1.524$ & 0.270 \\
\hline Higher & 1.268 & $0.966-1.666$ & 0.088 \\
\hline \multicolumn{4}{|l|}{ Mother's occupation } \\
\hline Not working & 1 & & \\
\hline Unskilled & 1.003 & $0.753-1.337$ & 0.983 \\
\hline Skilled & 0.786 & $0.506-1.222$ & 0.285 \\
\hline Professional/Technical/Managerial & 1.018 & $0.686-1.511$ & 0.930 \\
\hline \multicolumn{4}{|l|}{ Wealth index } \\
\hline Poorest & 1 & & \\
\hline Poorer & 0.974 & $0.652-1.455$ & 0.896 \\
\hline Middle & 1.026 & $0.692-1.520$ & 0.898 \\
\hline Richer & 1.330 & $0.894-1.979$ & 0.159 \\
\hline Richest & 1.588 & $1.036-2.435$ & 0.034 \\
\hline \multicolumn{4}{|l|}{ Type of residence } \\
\hline Rural & 1 & & \\
\hline Urban & 1.043 & $0.789-1.166$ & 0.675 \\
\hline \multicolumn{4}{|l|}{ Region } \\
\hline Islamabad Capital Territory & 1 & & \\
\hline Punjab & 1.911 & $1.457-2.506$ & $<0.001$ \\
\hline Sindh & 1.428 & $1.072-1.903$ & 0.009 \\
\hline KPK & 0.647 & $0.468-0.896$ & $<0.001$ \\
\hline Baluchistan & 0.376 & $0.228-0.622$ & $<0.001$ \\
\hline Gilgit Baltistan & 0.432 & $0.278-0.670$ & $<0.001$ \\
\hline \multicolumn{4}{|l|}{ Pregnancy complication } \\
\hline No & 1 & & \\
\hline Yes & 1.307 & $1.107-1.545$ & 0.002 \\
\hline \multicolumn{4}{|l|}{ Antenatal care utilization } \\
\hline None & 1 & & \\
\hline $1-3$ & 1.522 & $0.985-2.354$ & 0.059 \\
\hline
\end{tabular}


Table 3 Adjusted odd ratios for multivariable logistic regression of factors independently associated with among women aged 15-49 years $^{\mathrm{a}}$ (Continued)

\begin{tabular}{llll}
\hline Variables & AOR & $95 \% \mathrm{Cl}$ & $\mathrm{p}$-value \\
\hline More than 4 & 2.811 & $1.823-4.333$ & \\
Place of delivery & & & \\
Public & 1 & 0.001 & \\
Private & 1.052 & $0.883-1.254$ & 0.570 \\
\hline
\end{tabular}

Abbreviations: 1 reference category, AOR adjusted odds ratio, $\mathrm{Cl}$ confidence interval

${ }^{3}$ By using $\mathrm{X}^{2}$ test

${ }^{a}$ Multivariate logistic regression analysis was carried out to obtain AOR after entering all the independent variables simultaneously that were significant at level 0.05 in binary analysis

and non-medically indicated caesarean section deliveries in private and public hospital settings.

\section{Limitations}

The results of this study need to be considered in the light of several limitations. Firstly, the PDHS 2012-2013 does not provide data on the type of pregnancy complications a mother might experience during pregnancy. Owing to the scarcity of relevant information, this study could not identify any specific type of pregnancy complication that resulted in caesarean delivery. Secondly, the PDHS 2012-2013 data does not provide details of medical or non-medical reasons for performing caesarean sections. Therefore, the given data does not provide adequate information to relate the increase in the caesarean section rate with malpractice involving surgical procedures. Thirdly, owing to the cross-sectional design, the study could not assess the causal relationship between any of the independent variables and caesarean section deliveries. Moreover, the mothers' questionnaire does not provide information on the type of delivery (caesarean or vaginal) for each childbirth; so it could not be established whether a previous caesarean section emerged as one of reasons for a caesarean for the following deliveries or not.

\section{Conclusions}

Our study shows that the current CSR in Pakistan is approximately $14 \%$. Using data from the Pakistan Demographic and Health Survey 2012-13, our study revealed strong associations between maternal age, mother's education, region, pregnancy complications, utilisation of antenatal care, place of birth of a child, area of residence and the wealth profiles of mothers and the probability of caesarean section deliveries. It was found that women aged more than 24 years, having pregnancy complications, and utilising antenatal care more than four times during pregnancy were more likely to have a caesarean delivery. Furthermore, the results revealed that women living in an urban setting, residing in Punjab province, who were highly educated and had a better socioeconomic background were independently associated with caesarean delivery. The study has argued that there is an increasing misuse of caesarean interventions in both private and public hospitals in Pakistan. The present study recommends that, in order to reduce the escalating caesarean rate, a detailed medical justification for performing caesareans by doctors should be provided. Adequate awareness regarding the reduction of pregnancy complications can also help to reduce the chances of malpractice involving caesareans. Additionally, qualitative research needs to be conducted to understand the cultural beliefs, psychological factors and perceptions of Pakistani women that may be contributing to the upsurge in the CSR in Pakistan.

\section{Abbreviations}

AOR: adjusted odds ratio; Cl: confidence interval; CSR: caesarean section rate; OR: odds ratio; PDHS: Pakistan Demographic and Health Survey; WHO: World Health Organization

\section{Acknowledgements}

We acknowledge support of the publication fee by Deutsche Forschungsgemeinschaft and the Open Access Publication Funds of Bielefeld University.

\section{Availability of data and materials}

The analysis is based on secondary data, available from the Demographic and Health Survey program (https://dhsprogram.com/).

\section{Authors' contributions}

AA and UA drafted the initial manuscript. RZ supervised and reviewed manuscript writing and data analysis. AU, MZ and FF contributed in reviewing the final manuscript. All authors have read the manuscript. All authors read and approved the final manuscript.

\section{Ethics approval and consent to participate}

The study is based on a secondary data analysis based on data from PDHS 2012-13, a publicly available dataset. Therefore, an ethical approval is not required.

\section{Competing interests}

The authors declare that they have no competing interests.

\section{Publisher's Note}

Springer Nature remains neutral with regard to jurisdictional claims in published maps and institutional affiliations. 


\section{Author details}

'Institute of Social and Cultural Studies, University of the Punjab, Lahore, Pakistan. ${ }^{2}$ Department of Public Health Medicine, School of Public Health, Bielefeld University, Bielefeld, Germany.

\section{Received: 13 March 2018 Accepted: 12 April 2018}

Published online: 23 April 2018

\section{References}

1. Betran AP, Torloni MR, Zhang JJ, Gülmezoglu AM, for the WHO Working Group on Caesarean Section. WHO statement on caesarean section rates: a commentary. BJOG. 2015; https://doi.org/10.1111/1471-0528.13526.

2. Gibbons L, Belizán JM, Lauer JA, Betrán AP, Merialdi M, Althabe F. The global numbers and costs of additionally needed and unnecessary caesarean sections performed per year: overuse as a barrier to universal coverage. World Health Report 2010, Background Paper 30. Geneva, World Health Organization; 2010.

3. Neuman M, Alcock G, Azad K, et al. Prevalence and determinants of caesarean section in private and public health facilities in underserved South Asian communities: cross-sectional analysis of data from Bangladesh, India and Nepal. BMJ Open. 2014;4:e005982.

4. Nazir S. Determinants of cesarean deliveries in Pakistan, Pide working papers; 2015.

5. Qazi Q, Akhtar Z, Khan K, Khan AH. Pregnant women view regarding cesarean section in Northwest Pakistan. Tropical Medicine \& Surgery. 2013;1:105.

6. Ghosh S. Increasing trend in cesarean section delivery in India: role of medicalisation of maternal health, Working paper. Bangalore: Institute for Social and Economic Change; 2010.

7. Mishra US, Ramanathan M. Delivery-related complications and determinants of caesarean section rates in India. Health Policy Plan. 2002;17:90-8.

8. El-Ardat MA, Izetbegovic S, Mehmedbasic E, Duric M. Frequency of vaginal birth after cesarean section at clinic of gynecology and obstetrics in Sarajevo. Med Arh. 2013;67(6):435-7.

9. Nilsen C, Østbye T, Daltveit AK, Mmbaga BT, Sandøy IF. Trends in and sociodemographic factors associated with caesarean section at a Tanzanian referral hospital, 2000 to 2013. Int J Equity Health. 2014;13:87.

10. Karlström A, Nystedt A, Johansson M, Hildingsson I. Behind the myth-few women prefer caesarean section in the absence of medical or obstetrical factors. Midwifery, 2011:27:620-7.

11. Latifnejad RR, Zakerihamidi M, Merghati KE, Kazemnejad A. Cultural perceptions and preferences of Iranian women regarding cesarean delivery. Iranian J Nurs Midwifery Res. 2014;19:528-36.

12. Lori JR, Boyle JS. Cultural childbirth practices, beliefs, and traditions in postconflict Liberia. Health Care Women Int. 2011;32(6):454-73.

13. Béhague DP, Victora CG, Barros FC. Consumer demand for caesarean sections in Brazil: informed decision making, patient choice, or social inequality? A population based birth cohort study linking ethnographic and epidemiological methods. BMJ. 2002;324:942.

14. Mazzoni A, Althabe F, Liu NH, Bonotti AM, Gibbons L, Sanchez AJ. Women's preference for caesarean section: a systematic review and meta-analysis of observational studies. BJOG. 2011;118(4):391-9.

15. Ash A, Okah D. What is the right number of caesarean sections? Lancet 1997;349:1557.

16. Lauer JA, Betrán AP, Merialdi M, Wojdyla D. Determinants of caesarean section rates in developed countries: supply, demand and opportunities for control. Geneva: World Health Organization; 2010.

17. Buekens P. Over-medicalisation of maternal care in developing countries. In: De Brouwere V, Van Lerberghe W, editors. Safe, motherhood strategies: a review of the evidence. Antwerp: ITG Press; 2001. p. 195-206.

18. Johanson $R$, Newburn $M$, Macfarlane A. Has the medicalisation of childbirth gone too far? BMJ. 2002;324:892-5.

19. Pai M. Unnecessary medical interventions: caesarean sections as a case study. Econ Polit Wkly. 2000;35:2755-61.

20. Johnson EM, Rehavi MM. Physicians treating physicians: information and incentives in childbirth, NBER working paper; 2013.

21. NIPS. Pakistan demographic and health survey 2012-13. Islamabad: National Institute of Population Studies and Macro International Inc; 2008.

22. World Health Organization. Provision of effective antenatal care: integrated management of pregnancy and childbirth. Geneva: World Health Organization; 2006.
23. NIPS. Pakistan demographic and health survey 2006-2007. Islamabad: National Institute of Population Studies and Macro International Inc; 2008

24. Hafeez M, Yasin A, Badar N, Pasha MI, Akram N, Gulzar B. Prevalence and indications of caesarean section in a teaching hospital. JIMSA. 2014:27:15-6.

25. Iftikhar T, Rizvi U, Ejaz L. Evaluation of causes of increasing cesarean section rate in tertiary care hospital. J Sheikh Zayed Medical College. 2010;1:1.

26. Jabeen J, Mansoor MH, Mansoor A. Analysis of indications of cesarean sections. J Rawalpindi Medical College. 2013;17(1):101-3.

27. Martinez PA. C-section boom: all about the \$?. 2013. http://www.parents. com/blogs/everythingpregnancy/2013/09/04/must-read/cesarean-sectionbirth-monetary-incentive/. Accessed 19 Apr 2018.

28. Carolan M, Davey M-A, Biro MA, Kealy M. Older maternal age and intervention in labor: a population-based study comparing older and younger first-time mothers in Victoria, Australia. Birth. 2011;38(1):24-9.

29. Bayrambour $\mathrm{H}$, Heaman M. Advanced maternal age and the risk of cesarean birth: a systematic review. Birth. 2010;37(3):219-26.

30. Lin HC, Sheen TC, Tang CH, Kao S. Association between maternal age and the likelihood of a cesarean section: a population-based multivariate logistic regression analysis. Acta Obstet Gynecol Scand. 2004;83:1178-83.

31. Hanif HM. Association between maternal age and pregnancy outcome: implications for the Pakistani society. J Pak Med Assoc. 2011;61:313-9.

32. Ashraf-Ganjoei T, Mirzaei F, Anari-Dokht F. Relationship between prenatal care and the outcome of pregnancy in low-risk pregnancies. Open J Obstet Gynecol. 2011;1:109-12.

33. Padmadas SS, Suresh KS, Nair SB, Anitha Kumari KR. Cesarean section delivery in Kerala, India: Evidence from National Family Health Survey. Soc Sci Med Sci. 2000;519(4):511-21.

34. Sial MA. Increasing number of $\mathrm{C}$-sections crosses all danger thresholds. https://www.pakistantoday.com.pk/2012/01/08/increasing-number-of-csections-crosses-all-dangerthresholds/. Accessed 19 Apr 2018.

\section{Ready to submit your research? Choose BMC and benefit from:}

- fast, convenient online submission

- thorough peer review by experienced researchers in your field

- rapid publication on acceptance

- support for research data, including large and complex data types

- gold Open Access which fosters wider collaboration and increased citations

- maximum visibility for your research: over $100 \mathrm{M}$ website views per year

At BMC, research is always in progress.

Learn more biomedcentral.com/submissions 